\title{
The Development of A Flexible Battery by Using A Stainless Mesh Anode
}

\author{
Kaname Iwai, Teppei Tamura, Dang-Trang Nguyen, Kozo Taguchi*
}

Department of Electrical and Electronic Engineering, Ritsumeikan University, Japan

\begin{abstract}
We have developed a compact and flexible battery, which composes three parts: (1) an anode electrode made for stainless mesh which was heat-treated for $30 \mathrm{~min}$ at $500^{\circ} \mathrm{C}$ with coated carbon nanotube (CNT), (2) a piece of paper filter-based membrane with the pore size of $0.025 \mu \mathrm{m}$ and the thickness of $100 \mu \mathrm{m}$, and (3) a cathode electrode coated potassium ferricyanide. The battery can generate electricity activated by adding $50 \mu \mathrm{L}$ sodium chloride $(\mathrm{NaCl})$ solution to the anode. The battery has a $\mathrm{NaCl}$ concentration-dependence characteristic. In this research, we tested $0.5,1,3,5$, and $10 \% \mathrm{NaCl}$ solution, respectively. At $3 \% \mathrm{NaCl}$ concentration, the maximum power density and current density of $42.3 \mu \mathrm{W} / \mathrm{cm}^{2}$ and $228 \mu \mathrm{A} / \mathrm{cm}^{2}$ were obtained, respectively. After the experiments, there was a blue material encountered on the anode surface. By using EDS to analyze the blue material, it could be confirmed that the blue material was ferric ferrocyanide (Prussian blue). The operation principle of this battery was proposed as follows. First, on the anode side, the injected sodium chloride solution oxidizes the stainless mesh surface, then ferric ions and electrons are released. Second, on the cathode side, ferricyanide ions are reduced to ferrocyanide ions by electrons coming from the anode through the external circuit. Simultaneously, ferric ions react with ferrocyanide ions to produce Prussian blue and generate more electrons. This battery can be potentially utilized for applications that require on-demand, disposable, and flexible characteristics. O2019. CBIORE-IJRED. All rights reserved
\end{abstract}

Keywords: flexible, stainless mesh, $\mathrm{NaCl}$, Prussian blue, potassium ferricyanide

Article History: Received: Sept 11, 2019; Revised: Oct 20, 2019; Accepted: Oct 25, 2019; Available online: Oct 30, 2019

How to Cite This Article: Iwai, K., Tamura, T., Nguten, D-T. and Taguchi, K. (2019) The Development of A Flexible Battery by Using A Stainless Mesh Anode. International Journal of Renewable Energy Development, 8(3), 225-229.

https://doi.org/10.14710/ijred.8.3.225-229

\section{Introduction}

The widespread use of flexible electronic devices urgently enhances the requirements for flexible material such as flexible electrodes, separators, and battery packing (Long et al., 2018). Conventional tool steels are widely applied to manufacture cutters and wear-resistant components because of their high hardness, high strength, and well wear resistance. However, corrosion resistance limits their use in certain service environments, such as saline solutions (Wei, Liu, Li, \& Cheng, 2019). On the other hand, atmospheric corrosion is characterized by electrochemical degradation of metal in the presence of droplets or thin films of electrolytes (Tang et al., 2019).

Most metallic materials are usually used either in the industry as materials of construction or in medical treatment as orthopedic implant devices, rely on the presence of passive films on their surface to develop good corrosion resistance (Omanovic \& Roscoe, 1999). Electrochemical techniques have been widely employed in accelerated corrosion studies (Sousa \& Barbosa, 1991). Among the factors influencing corrosion, stress is of vital importance as it accelerates the failure of metals suffering from pitting corrosion (Guo, Wang, \& Han, 2018).

It is renown that chloride solutions are among the most aggressively corrosive environments (Kocijan, Milosev, \&
Pihlar, 2003). The corrosion rate of steels in neutral $\mathrm{NaCl}$ solutions is initiated through two main mechanisms: formation and build-up of a passivating iron oxide layer and partial destruction of this layer by pitting (Scotto, Cintio, \& Marcenaro, 1985). It is generally accepted that pitting corrosion is preceded by the appearance of tiny corrosion seeds on the metal surface, which is naturally protected by an oxide layer. At ambient conditions, a thin protective oxide film forms on the surface of mild steel. Unlike that formed on stainless steels, it is not protective in the presence of electrolytes and it usually breaks down (Cáceres, Vargas, \& Herrera, 2009). It was found that in $3.5 \% \mathrm{NaCl}$ solution, the effect of corrosion on the overall cavitation erosion-corrosion was most pronounced in mild steel and grey cast iron and negligible in stainless steel (Kwok, Cheng, \& Man, 2000). For example, 3\% $\mathrm{NaCl}$ solution is equal to the concentration of seawater, $0.5 \%$ $\mathrm{NaCl}$ is equal to the concentration of $\mathrm{NaCl}$ in human sweat. The development of this corrosion product can have a significant effect on the dissolution behavior of the underlying steel (Barker et al., 2019). The steel's performance in oxidizing environments is well established, but its behavior in corrosive environments, particularly those containing sulfiding species and

\footnotetext{
* Corresponding author: taguchi@se.ritsumei.ac.jp (Kozo Taguchi)
} 
chlorides have not been studied extensively (Tsaur, Rock, Wang, \& Su, 2005).

Stainless steel mesh is low-cost containing mainly iron and can be used as an outstanding flexible substrate after chemical treatment to modify its surface. The metal, iron, can be easily oxidized to $\mathrm{Fe}_{2} \mathrm{O}_{3}$ (Shinata, Takahashi, \& Hashiura, 1987). As one of the common anode materials in energy storage devices, $\mathrm{Fe}_{2} \mathrm{O}_{3}$ has many advantages, such as low toxicity, low-cost, and high theoretical capacity (Long et al., 2018). The reaction is shown below (Eq. (1)).

$2 \mathrm{Fe}+3 \mathrm{H}_{2} \mathrm{O} \rightarrow \mathrm{Fe}_{2} \mathrm{O}_{3}+6 \mathrm{H}^{+}+6 e^{-}$

In this paper, we developed a flexible battery with a stainless mesh-based anode. The battery was activated by dropping $\mathrm{NaCl}$ solution to the anode. A stable output was obtained for more than one hour. After the operation, there was a blue material that emerged on the anode surface - the blue material was analyzed by energydispersive X-ray spectroscopy (EDS).

\section{Materials and Methods}

\subsection{Battery design and materials}

The design of the battery is shown in Fig. 1. The battery composed of three main parts: an anode electrode, a membrane, and a cathode electrode.

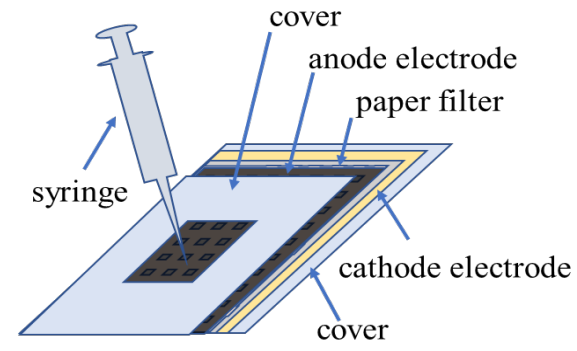

Fig. 1 Battery design

The anode electrode $(10 \mathrm{~mm} \times 10 \mathrm{~mm})$ were made of stainless mesh (PS100-321, HIKARI, Japan), which was heat-treated at $500^{\circ} \mathrm{C}$ for $30 \mathrm{~min}$ (Fig. 2). After heattreatment, the color of stainless mesh changed to dark brown color, which is the color of $\mathrm{Fe}_{2} \mathrm{O}_{3}$. Moreover, it was dip-coated in multiwalled carbon nanotube dispersion solution (CNT, N7006L, KJ Specialty Paper, Japan) for 1 min, and dried at room temperature (Fig. 3). The CNT network provides high conductivity and flexibility (Cui, $\mathrm{Hu}$, Choi, \& Cui, 2010).

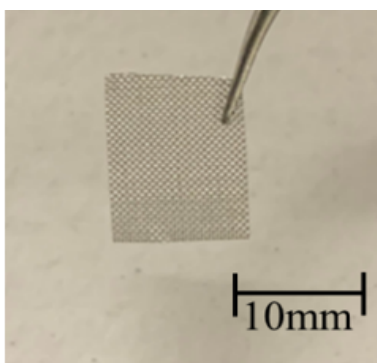

(a)

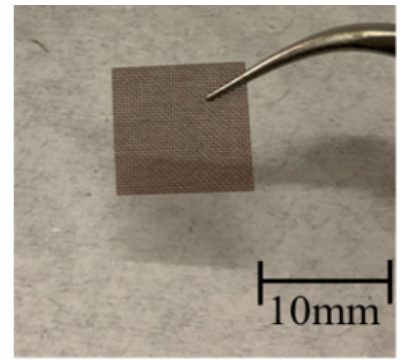

(b)
Fig. 2 Photo images of stainless mesh (a) before and (b) after heat treatment

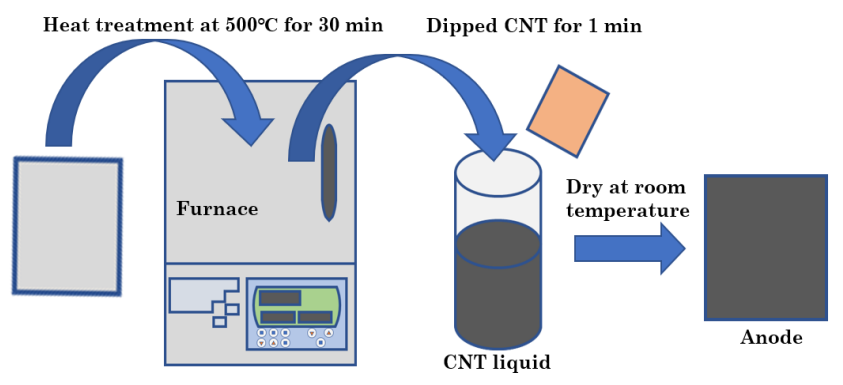

Fig. 3 The process of making the anode electrode

The cathode electrode $(10 \mathrm{~mm} \times 10 \mathrm{~mm})$ was made of hydrophilic carbon sheets and potassium ferricyanide (Wako, Japan). Hydrophilic carbon sheet was dipped into potassium ferricyanide $0.75 \mathrm{M}$ for $1 \mathrm{~min}$ and dried at $60^{\circ} \mathrm{C}$ for $20 \mathrm{~min}$ (Fig. 4). Potassium ferricyanide was used as the electron acceptor at the cathode. The reduction reaction of ferricyanide ions to ferrocyanide ions is as follows (Eq. (2)).

$\left[\mathrm{Fe}(\mathrm{CN})_{6}\right]^{3-}+e^{-} \rightarrow\left[\mathrm{Fe}(\mathrm{CN})_{6}\right]^{4-}$

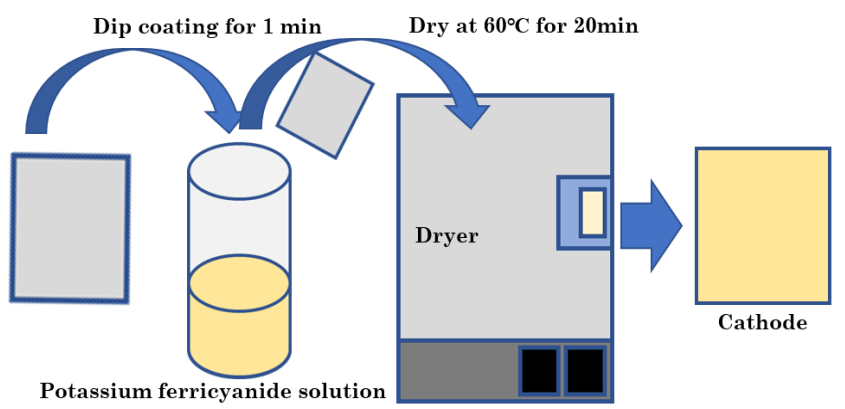

Fig. 4 The process of making cathode electrodes

Paper filter $(0.025 \mu \mathrm{m}$ pore size and $100 \mu \mathrm{m}$ thickness $)$ (VSWP09025, Merck, Japan) was used to make the paperbased membrane $(15 \mathrm{~mm} \times 15 \mathrm{~mm})$. The flexibility of stainless mesh and the battery is shown in Fig. 5. It can be seen that the battery can be bent easily.

The battery cover was made of silicone rubber $(15 \mathrm{~mm}$ $\times 15 \mathrm{~mm} \times 2 \mathrm{~m}$ ) (Monotaro, Japan). On the anode side, the cover was cut a hole $(5 \mathrm{~mm} \times 5 \mathrm{~mm})$ for injecting aqueous sodium chloride solution to the anode to activate the battery.

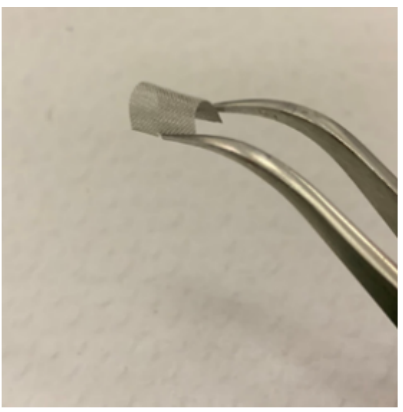

(a)

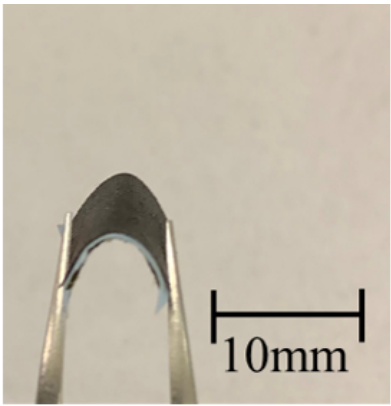

(b)
Fig. 5 Flexibility of (a) stainless mesh and (b) the battery without the cover

\subsection{Experimental setup}

The experimental setup is shown in Fig. 6. An external resistor was connected between the anode and cathode to 
discharge the battery. The voltage between the anode and cathode was measured with a data acquisition system (DAQ, National Instrument, USB-6211), and recorded every $30 \mathrm{sec}$ via a customized LabView interface. The current through the resistor was calculated using Ohm's law. To measure the power density curves, we connected respectively $80 \mathrm{k} \Omega, 50 \mathrm{k} \Omega, 12 \mathrm{k} \Omega, 5 \mathrm{k} \Omega, 2.6 \mathrm{k} \Omega, 810 \Omega, 380$ $\Omega, 150 \Omega$, and $47 \Omega$ resistors to the external circuit to discharge the battery. The discharging voltage was recorded to calculate the power density. For each experiment, at least three samples were examined, and the average result was used in this paper.

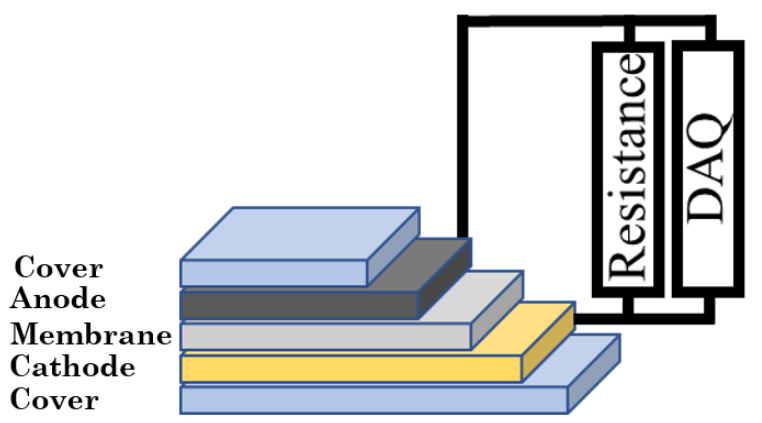

Fig. 6 Experimental setup

\section{Results and Discussions}

\subsection{Blue material on the anode after the experiment}

After the experiment, we encountered a blue material on the anode electrode (Fig. 7).

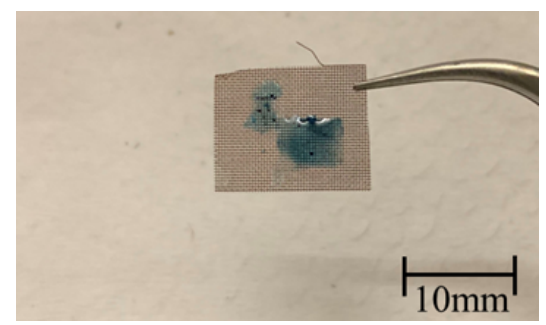

Fig. 7 Photo image of the anode electrode without CNT after the experiment

We suspected that this material was mainly composed of Prussian blue $\left(\mathrm{Fe}_{4}\left[\mathrm{Fe}(\mathrm{CN})_{6}\right]_{3}\right)$, which is generated from the reaction between $\mathrm{Fe}_{2} \mathrm{O}_{3}$ and ferrocyanide ions $\left(\left[\mathrm{Fe}(\mathrm{CN})_{6}\right]^{4-}\right)$ as shown in Eq. (3). Prussian blue is usually used in the painting industry.

$2 \mathrm{Fe}_{2} \mathrm{O}_{3}+6 \mathrm{H}_{2} \mathrm{O}+3\left[\mathrm{Fe}(\mathrm{CN})_{6}\right]^{4-} \rightarrow\left[\mathrm{Fe}(\mathrm{CN})_{6}\right]_{3}+12 \mathrm{OH}^{-}+$ $12 e$

\subsection{EDS characterization}

To confirm the presence of Prussian blue, we collected the blue material from the anode electrode after the experiment and analyzed it by EDS coupled with scanning electron microscopy (SEM) (SU-1500, Hitachi, Japan). Fig. 8 shows the collected blue material generated on the anode electrode after the experiment. Its elemental composition was analyzed by EDS.

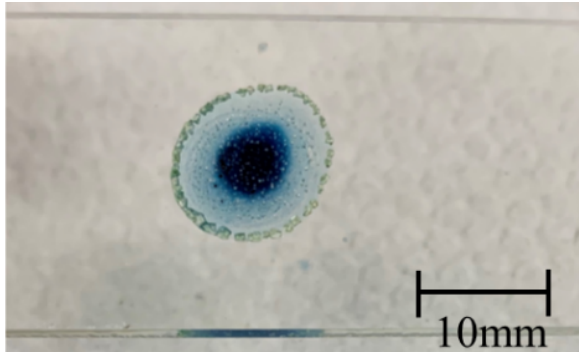

Fig. 8 Photo image of the blue material used for EDS measurement

Fig. 9 (a) shows the SEM image of the blue material. Fig 9 (b) shows the elemental spectrum pattern of the blue material. The qualitative elemental composition is listed in table 1. From these results, it can be confirmed that eight elements existed in the sample. The stainless mesh composed of $\mathrm{Fe}, \mathrm{Cr}, \mathrm{Ni}$, and $\mathrm{O}$. Prussian blue composed of $\mathrm{Fe}, \mathrm{C}$, and $\mathrm{N}$. Furthermore, $\mathrm{Na}$ and $\mathrm{Cl}$ were originated from the injected saline solution for battery activation. Based on the unique blue color and measured elemental composition of the material, it can be confirmed that there was the existence of Prussian blue in the sample. Therefore, the reaction expressed in Eq. (3) has occurred during the experimental process.

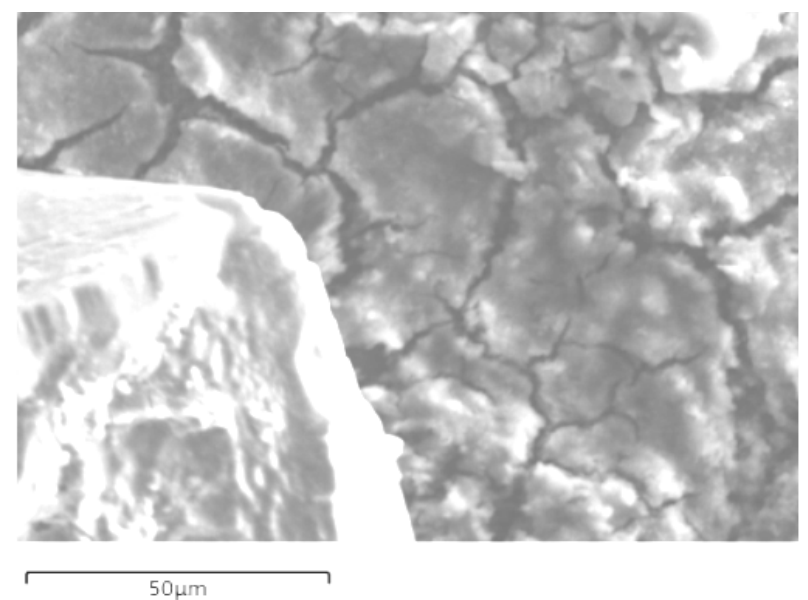

(a)

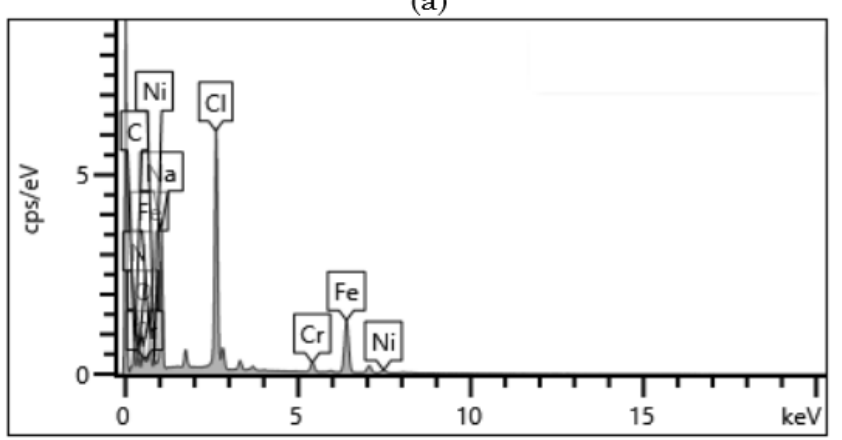

(b)

Fig. 9 The SEM image (a) and the elemental spectrum (b) of the blue material

Fig. 10 shows the elemental mapping of the blue material mapped by EDS. From Fig. 10 (g) and (h), there was the presence of $\mathrm{NaCl}$ crystal at the lower left. 


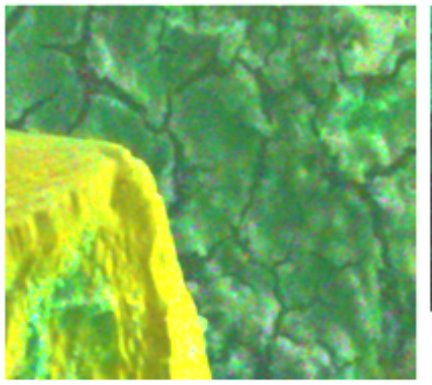

(a)

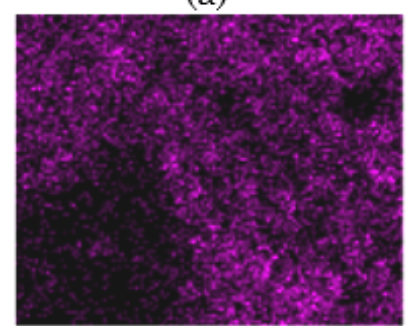

(c)
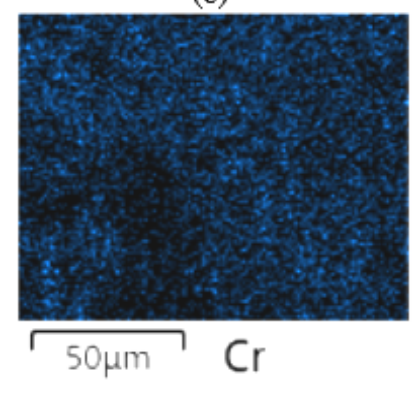

(e)

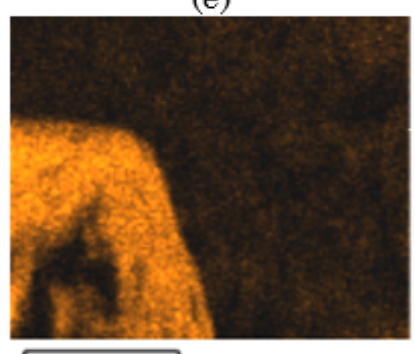

$50 \mu \mathrm{m} N$

(g) $\longdiv { 5 0 \mu \mathrm { m } } \mathrm { C }$
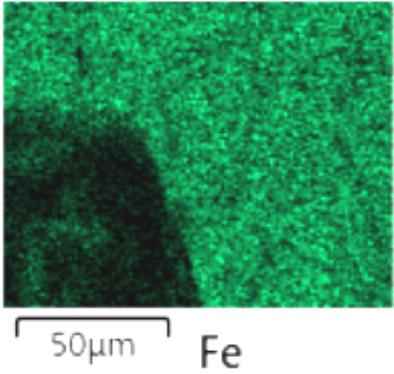

(b)

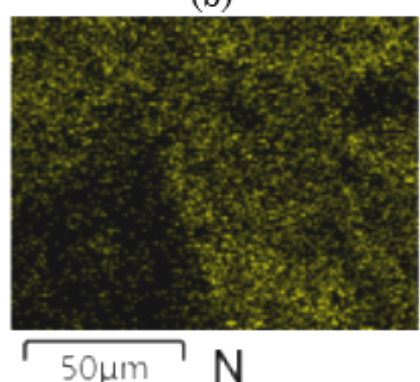

(d)
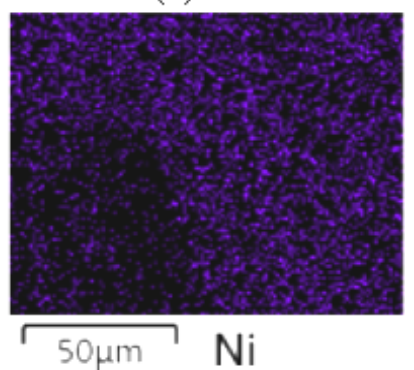

(f)

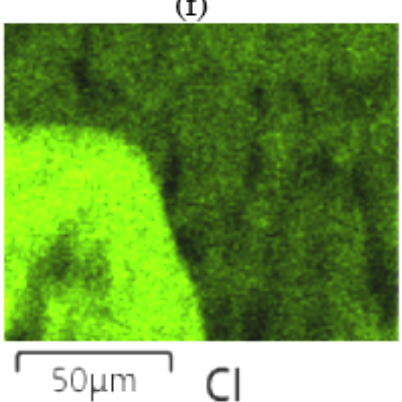

(h)
Fig. 10 Elemental mapping of the blue material

Table 1

Elemental composition of the blue material

\begin{tabular}{cc}
\hline Element & wt\% \\
\hline $\mathrm{C}$ & 19.53 \\
$\mathrm{O}$ & 18.37 \\
$\mathrm{Na}$ & 10.78 \\
$\mathrm{Cl}$ & 15.24 \\
$\mathrm{Cr}$ & 17.48 \\
$\mathrm{Fe}$ & 1.85 \\
$\mathrm{Ni}$ & 15.50 \\
$\mathrm{Total}:$ & 1.26 \\
\end{tabular}

Prussian blue was generated from the reaction at the anode electrode between $\mathbf{F e}_{2} \mathbf{O}_{3}$ and potassium ferrocyanide ions coming from the cathode electrode (Eq. 3 ). This reaction is expected to have a positive contribution to the electricity generation of the battery.

\subsection{Characteristics of the anode}

To justify the operation principle of the battery, we investigated the performance of two types of anode electrodes: (i) heat-treated stainless mesh without CNT coating, and (ii) heat-treated stainless mesh with CNT coating. Fig. 11 displays the discharging voltage (discharged by an $810 \Omega$ resistor) generated by those two anode electrodes. The anode (i) showed a lower output than that of the anode (ii). This result may be attributed to the binding and electron-collecting characteristics of CNT. Thus, the anode (ii) also had a shorter startup time than that of the anode (i). Based on this result, the anode electrode with heat-treatment and CNT coating could produce higher power.

Moreover, the heat-treatment process is necessary for the creation of a layer of $\mathrm{Fe}_{2} \mathrm{O}_{3}$ on the surface of the stainless mesh. The layer of $\mathrm{Fe}_{2} \mathrm{O}_{3}$ is important for the reaction in Eq. (3), which produces mainly electricity for the battery.

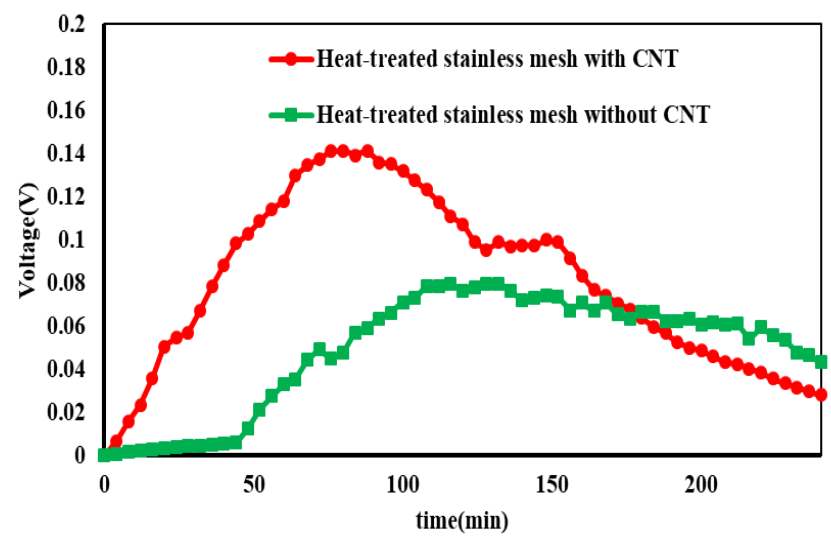

Fig. 11 Performance of two types of anode electrodes

\section{4 $\mathrm{NaCl}$ concentration and the performance of the battery}

In this section, we evaluated the impact of the concentration of the injected $\mathrm{NaCl}$ solution on the generated power density of the battery. Five concentrations of $\mathrm{NaCl}$ solution $(0.5,1,3,5$, and $10 \%)$ were tested. An appropriate amount of $\mathrm{NaCl}$ was dissolved in deionized water to obtain the desired concentration. In this experiment, the anode electrode was heat-treated stainless mesh with CNT. The power density curves are shown in Fig. 12. As the $\mathrm{NaCl}$ concentration increased from 0.5 to $3 \%$, the power density increased. However, it decreased when the $\mathrm{NaCl}$ concentration increased by more than $3 \%$. This result may be due to $\mathrm{NaCl}$ crystal covers up the anode surface faster at higher $\mathrm{NaCl}$ concentration. As a result, there is a less active area for the reactions in Eqs. (1) and (3) leading to lower the power density.

Based on this experimental result, $3 \%$ was the optimum $\mathrm{NaCl}$ concentration. The maximum power density of the battery obtained at $3 \% \mathrm{NaCl}$ concentration was $42.3 \mu \mathrm{W} / \mathrm{cm}^{2}$ obtained at $810 \Omega$ external resistance. 


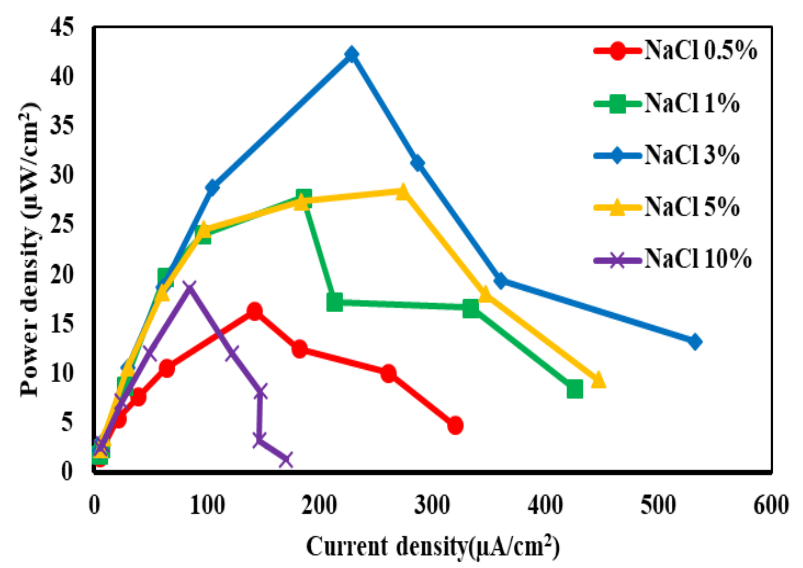

Fig. 12 The power density curves of the battery activated by five $\mathrm{NaCl}$ solution concentrations

\section{Conclusion}

In this paper, we made a flexible battery that used heattreated stainless mesh with CNT coating as the anode electrode. The operation principle of electricity generation from the creation of Prussian blue on the anode was discussed. The concentration of the injected $\mathrm{NaCl}$ solution for activation was also examined. At $3 \% \mathrm{NaCl}$ concentration, the maximum power density and current density of the battery were $42.3 \mu \mathrm{W} / \mathrm{cm}^{2}$ and $228 \mu \mathrm{A} / \mathrm{cm}^{2}$, respectively. Moreover, the importance of heat-treatment and CNT coating processes of the anode electrode was also investigated.

\section{References}

Barker, R., Al Shaaili, I., De Motte, R. A., Burkle, D., Charpentier, T., Vargas, S. M., \& Neville, A. (2019). Iron carbonate formation kinetics onto corroding and pre-filmed carbon steel surfaces in carbon dioxide corrosion environments. Applied Surface Science, 469, 135-145. https://doi.org/10.1016/j.apsusc.2018.10.238

Cáceres, L., Vargas, T., \& Herrera, L. (2009). Influence of pitting and iron oxide formation during corrosion of carbon steel in unbuffered $\mathrm{NaCl}$ solutions. Corrosion Science, 51(5), 971978. https://doi.org/10.1016/j.corsci.2009.02.021

Cui, L. F., Hu, L., Choi, J. W., \& Cui, Y. (2010). Light-weight freestanding carbon nanotube-silicon films for anodes of lithium ion batteries. ACS Nano, 4(7), 3671-3678. https://doi.org/10.1021/nn100619m
Guo, S., Wang, H., \& Han, E. H. (2018). Computational evaluation of the influence of various uniaxial load levels on pit growth of stainless steel under mechanoelectrochemical interactions. Journal of the Electrochemical Society, 165(9), 515-523. https://doi.org/10.1149/2.1071809jes

Kocijan, A., Milosev, I., \& Pihlar, B. (2003). The influence of complexing agent and proteins on the corrosion of stainless steels and their metal components. Journal of Materials Science. Materials in Medicine, 14(1), 69-77. Retrieved from http://www.ncbi.nlm.nih.gov/pubmed/15348541

Kwok, C. T., Cheng, F. T., \& Man, H. C. (2000). Synergistic effect of cavitation erosion and corrosion of various engineering alloys in $3.5 \% \mathrm{NaCl}$ solution. Materials Science and Engineering $\quad A, \quad 290(1-2), \quad 145-154$. https://doi.org/10.1016/S0921-5093(00)00899-6

Long, B., Yang, H., Wang, F., Mao, Y., Balogun, M. S., Song, S., \& Tong, Y. (2018). Chemically-modified stainless steel mesh derived substrate-free iron-based composite as anode materials for affordable flexible energy storage devices. Electrochimica Acta, 284, 271-278. https://doi.org/10.1016/j.electacta.2018.07.097

Omanovic, S., \& Roscoe, S. G. (1999). Electrochemical studies of the adsorption behavior of bovine serum albumin on stainless steel. Langmuir, 15(23), 8315-8321. https://doi.org/10.1021/la990474f

Scotto, V., Cintio, R. Di, \& Marcenaro, G. (1985). The influence of marine aerobic microbial film on stainless steel corrosion behaviour. Corrosion Science, 25(3), 185-194. https://doi.org/10.1016/0010-938X(85)90094-0

Shinata, Y., Takahashi, F., \& Hashiura, K. (1987). NaCl-induced hot corrosion of stainless steels. Materials Science and Engineering, 87(C), 399-405. https://doi.org/10.1016/00255416(87)90404-6

Sousa, S. R., \& Barbosa, M. A. (1991). Electrochemistry of AISI 316L stainless steel in calcium phosphate and protein solutions. Journal of Materials Science: Materials in Medicine, 2(1), 19-26. https://doi.org/10.1007/BF00701683

Tang, X., Ma, C., Zhou, X., Lyu, X., Li, Q., \& Li, Y. (2019). Atmospheric corrosion local electrochemical response to a dynamic saline droplet on pure Iron. Electrochemistry Communications, 101, 28-34. https://doi.org/10.1016/j.elecom.2019.01.011

Tsaur, C. C., Rock, J. C., Wang, C. J., \& Su, Y. H. (2005). The hot corrosion of 310 stainless steel with pre-coated $\mathrm{NaCl} / \mathrm{Na}$ 2so 4 mixtures at $750^{\circ} \mathrm{C}$. Materials Chemistry and Physics, $89(2-3)$, $445-453$. https://doi.org/10.1016/j.matchemphys.2004.10.002

Wei, L., Liu, Y., Li, Q., \& Cheng, Y. F. (2019). Effect of roughness on general corrosion and pitting of (FeCoCrNi)0.89(WC)0.11 high-entropy alloy composite in 3.5 wt.\% NaCl solution. Corrosion Science, 146, 44-57. https://doi.org/10.1016/j.corsci.2018.10.025 